\title{
Towards Qualification of Friction Stir Welding to AA5083-O and AA5052-O Aluminum Alloys
}

\author{
Guilherme Sangalli, Guilherme Vieira Braga Lemos, ${ }^{b, *}$, Douglas Martinazzi ${ }^{b}$ Cleber Rodrigo de \\ Lima Lessa ${ }^{c}$, Arthur Bortolin Beskow ${ }^{a}$, Afonso Reguly ${ }^{b}$ \\ ${ }^{a}$ Universidade Regional Integrada do Alto Uruguai e das Missões (URI), Fátima, Erechim, RS, Brasil \\ ${ }^{b}$ Laboratório de Metalurgia Física (LAMEF), Programa de Pós-Graduação em Engenharia de Minas, \\ Metalúrgica e de Materiais (PPGE3M), Universidade Federal do Rio Grande do Sul (UFRGS), Porto \\ Alegre, RS, Brasil \\ 'Instituto Federal do Rio Grande Do Sul (IFRS), Caxias do Sul, RS, Brasil
}

Received: May 22, 2019; Revised: August 14, 2019; Accepted: September 18, 2019

\begin{abstract}
Friction Stir Welding (FSW) is an excellent alternative for joining dissimilar and similar materials in comparison to conventional welding processes. In this sense, this work aims at qualifying FSW to similar AA5083-O and AA5052-O aluminum alloys, with $6.35 \mathrm{~mm}$ thickness, in a CNC machining center. Therefore, four welding experiments were undertaken. At first, two types of plate surface finish were considered before joining. Afterward, two tool probe geometries, and changes in the base material position were evaluated. Hence, the welds were mainly analyzed by metallography, tensile testing, and bending tests. Results showed that the machining step to oxides removal and plates alignment is beneficial for the weld processing and the factor that has significant influence to achieve suitable joints is the tool probe geometry. Finally, by obtaining an average ultimate tensile strength (UTS) of around $191 \mathrm{MPa}$, enhanced microhardness, and bent angle of approximately $150^{\circ}$, the best joint was chosen.
\end{abstract}

Keywords: Friction stir welding, aluminum alloys, CNC machining center, weld qualification.

\section{Introduction}

One of the main focuses of the metal industry is weight reduction and, in this scenario, aluminum has a density about three times smaller than steel as well as excellent mechanical properties $^{1}$. Welding of aluminum alloys can be relatively difficult due to several factors that may hinder the achievement of a high-quality joint ${ }^{2}$. Therefore, the formation of defects such as cracks, porosities, and deterioration in mechanical properties resulting from traditional welding processes is due, in large part, to the higher heat input imposed, making the use of these techniques sometimes unattractive to industry ${ }^{3,4}$. As a consequence, different joining methods are used, such as riveted, screwed joints, amongst others ${ }^{5}$. Another noticeable difficulty encountered by traditional fusion joining processes is to weld materials with differences in their chemical compositions, hardness, UTS, melting point and which are commonly known as dissimilar materials.

As an alternative for dissimilar welding, FSW has been drawing attention, a process which achieves lower heat input. This thermomechanical processing employs a nonconsumable tool to promote the material's mixing in the hot plasticized state to produce the sound joint. Moreover, the joint is formed as a response to frictional heat and forging force between the tool and the plates to be welded, where the temperatures reached are usually below the material's melting point ${ }^{2}$. Therefore, this method is carried out in a solid-state manner ${ }^{6}$, i.e., the material reaches temperatures

*e-mail: guilherme.lemos@ufrgs.br sufficient for recrystallization to occur theoretically without melting. Furthermore, FSW attractive characteristics have expanded its application to world-renowned companies such as $\mathrm{NASA}^{7}, \mathrm{BMW}^{8}$, Ford $^{8}$, Volvo $^{8}$, Audi $^{9}$, Airbus $^{10}$, Apple $^{11}$, among others. Recently, authors ${ }^{6}$ have suggested that there is an emergent potential of applying this technique to oil and gas pipes. Still, various alloys can be welded, among them, it can be mentioned steel ${ }^{12}$ and nonferrous ones such as $\mathrm{Al}^{13,14,15,16,17}, \mathrm{Ti}^{18}$ and $\mathrm{Ni}^{6,19,20}$. Finally, this process can be a solution for joining dissimilar materials such $\mathrm{Ti}$ and $\mathrm{Al}^{21}$, $\mathrm{Al}$ and $\mathrm{Mg}^{22}, \mathrm{Al}$ and $\mathrm{Cu}^{23}$, which proves a unique welding perspective by this technology.

The present work focuses on FSW application for similar Al alloys and the subsequent qualification of the welds processed. Hence, four welding experiments were performed based on process parameters, pre-finishing of the aluminum plates, tool probe geometry, and base materials position (advancing side (AS) or retreating side (RS)).

\section{Materials and Methods}

Aluminum plates (AA5052-O and AA5083-O alloys) of distinct chemical compositions were joined in the current work. These alloys belong to $5 \mathrm{xxx}$ series, are considered not hardened by heat treatment (precipitation) and were called similar materials since they contain essentially the same alloying elements, but in different quantities. In this context, Table 1 shows the chemical composition of these alloys. Furthermore, the mechanical properties of AA 5052 and AA 5083 alloys are presented in Table 2. 
Table 1. Chemical composition of aluminum alloys ${ }^{24}$.

\begin{tabular}{lccccccccc}
\hline Material & $\mathbf{S i}$ & $\mathbf{F e}$ & $\mathbf{C u}$ & $\mathbf{M n}$ & $\mathbf{M g}$ & $\mathbf{C r}$ & $\mathbf{Z n}$ & $\mathbf{T i}$ & $\mathbf{A l}$ \\
\hline AA5052 & 0.25 & 0.4 & 0.1 & 0.1 & $2.2-2.8$ & $0.15-0.35$ & 0.1 & 0 & Bal. \\
AA5083 & 0.4 & 0.4 & 0.1 & $0.4-1$ & $4.0-4.9$ & $0.05-0.25$ & 0.25 & 0.15 & Bal. \\
\hline
\end{tabular}

Table 2. Mechanical properties of AA5052-O and AA5083-O alloys ${ }^{25}$.

\begin{tabular}{lcc}
\hline Properties & AA5052-O & AA5083-O \\
\hline Ultimate tensile strength (MPa) & $170-220$ & $275-350$ \\
Yield strength (MPa) & Min 65 & $125-200$ \\
Brinell hardness (HB) & 47 & 60
\end{tabular}

Friction stir welds were produced by a Computer Numerical Control (CNC) machining center at URI-Erechim. This SKYBULL 600 equipment has three axes of movement $(\mathrm{x}, \mathrm{y}, \mathrm{z})$ and was made by Diplomat (Figure 1). The friction stir processing parameters were tool rotational speed of 1450 $\mathrm{rpm}$ and welding speed of $20 \mathrm{~mm} / \mathrm{min}$.

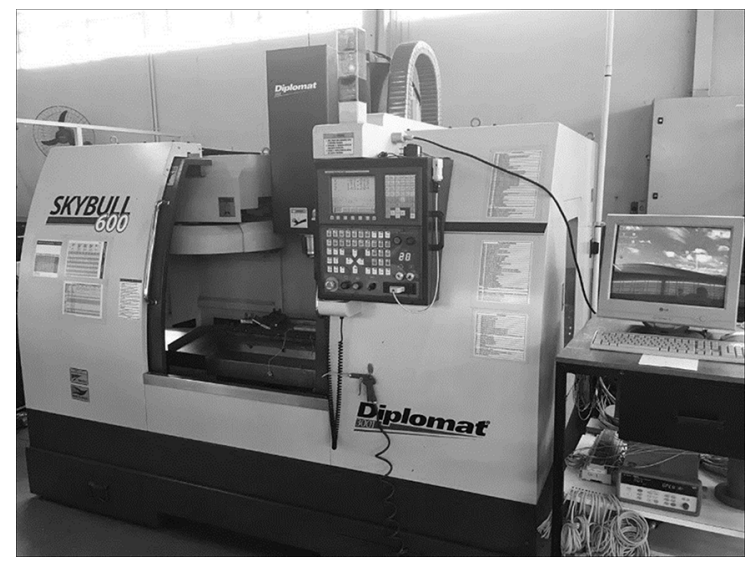

Figure 1. SKYBULL 600 CNC machine center.

The four welding attempts are summarized in Table 3, and their main characteristics were:

- Machining of plates surfaces to align the joint and removal of oxides and impurities. This step was carried out in the same FSW machine, after fixing the base material on the table, but before joining. Therefore, $0.3 \mathrm{~mm}$ thickness was removed by a milling cutter of $20 \mathrm{~mm}$ diameter;

- Two tool probe geometries;

- Changes in the position of the base material, located on the AS or RS.

Table 3. Overview of friction stir welding experiments.

\begin{tabular}{lcccc}
\hline & \multicolumn{4}{c}{ Welding trials } \\
\cline { 2 - 5 } Characteristics & Weld G1 & Weld G2 & Weld G3 & Weld G4 \\
\hline Probe & 1 & 1 & 2 & 2 \\
Surface finishing & --- & $0.3 \mathrm{~mm}$ & $0.3 \mathrm{~mm}$ & $0.3 \mathrm{~mm}$ \\
Plates thickness & $6.35 \mathrm{~mm}$ & $6.05 \mathrm{~mm}$ & $6.05 \mathrm{~mm}$ & $6.05 \mathrm{~mm}$ \\
BM on the RS & AA5083 & AA5083 & AA5083 & AA5052 \\
BM on the AS & AA5052 & AA5052 & AA5052 & AA5083 \\
\hline
\end{tabular}

Processing parameters such as welding speed, tool rotational, and shoulder penetration did not change in the welding experiments. Still, the tilt angle was $0^{\circ}$, and the axial force was not monitored. It should also be mentioned that this work emphasis on the qualification of the welds, as suggested by ISO $25239-4^{26}$.

The tool had a shoulder with $19 \mathrm{~mm}$ diameter and $2 \times 45^{\circ}$ bevel, with spiral striations to facilitate the materials to be forged to the center of the joint as well as allowing a more homogeneous mixing. Two probe variations were employed, as shown in Figure 2. Therefore, probe 1 (Figure 2a) is a three-sided threaded cam pin, $6.6 \mathrm{~mm}$ diameter at the base, $3.5 \mathrm{~mm}$ diameter at the tip and an effective length of 6.6 $\mathrm{mm}$, containing an M6 right-hand thread profile throughout its length. On the other hand, probe 2, shown in Figure 2b, is a threaded-tapered probe with $6 \mathrm{~mm}$ diameter at the base, $4 \mathrm{~mm}$ diameter at the tip and an effective length of $6.2 \mathrm{~mm}$, containing an M6 right-hand thread profile throughout its extension. The material of the shoulder and probes was AISI VC 131 steel.
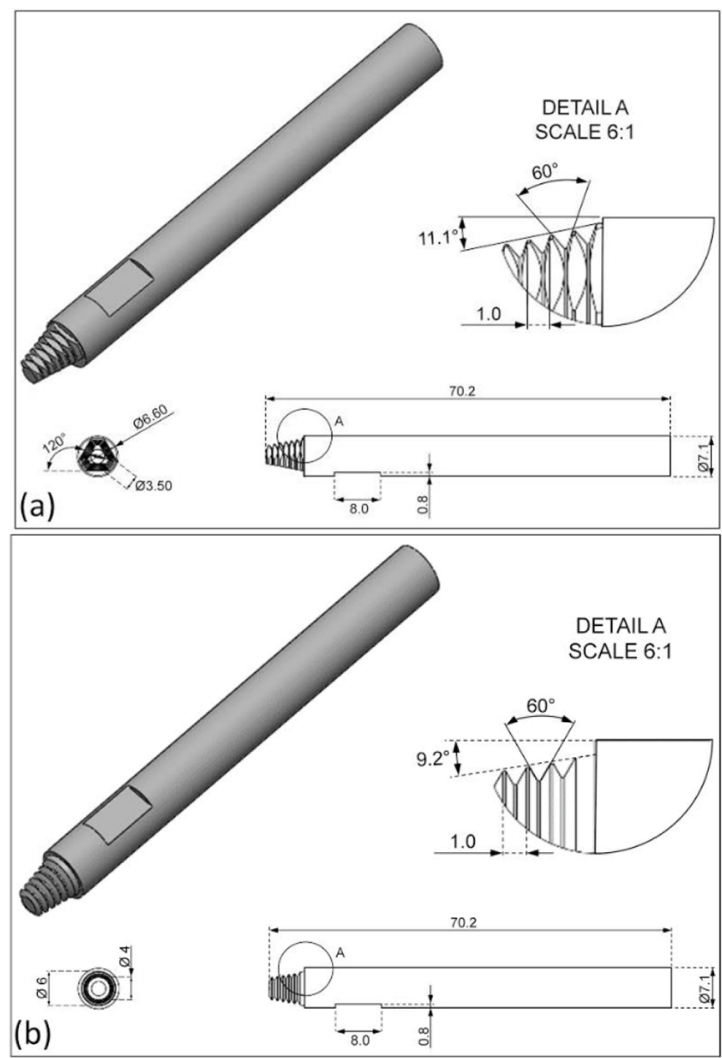

Figure 2. Schematic sketch of the tool probes employed: (a) probe 1 , (b) probe 2. 
The plate dimensions were $310 \mathrm{~mm}$ length, $100 \mathrm{~mm}$ width, and $6.35 \mathrm{~mm}$ thickness. Therefore, two plates were used for producing the joints. From the $310 \mathrm{~mm}$ length, the initial 10 $\mathrm{mm}$ and the final $20 \mathrm{~mm}$ of the welds were eliminated. From the remaining $280 \mathrm{~mm}$ length, 13 specimens were obtained, as presented in Figure 3. These samples were used to the analyzes mentioned below (macrostructure, tensile testing, and bending tests). Before the sample's sectioning, a surface machining process was carried out to remove $0.1 \mathrm{~mm}$ from the weld top surface region and, consequently, to eliminate the flash.

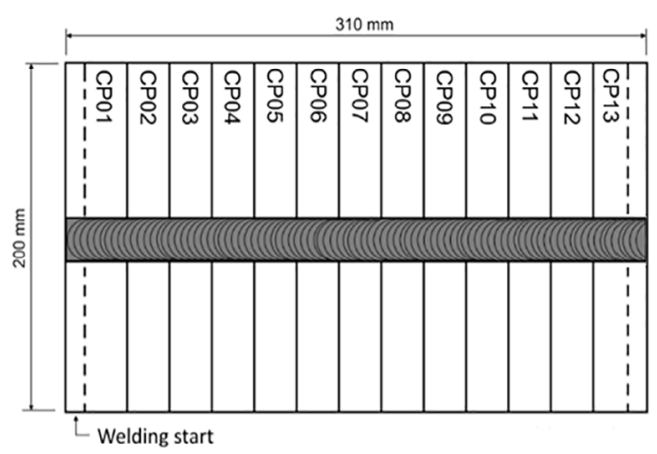

Figure 3. Specimens distribution along the welds.

For the macrostructural analyzes, the samples were prepared according to the basic metallographic practices and etched by aqua regia (distilled water, nitric acid, and hydrochloric acid). These macrostructural observations were done in all specimens.

Tensile tests were performed, considering $\mathrm{CP} 03, \mathrm{CP} 06$, $\mathrm{CP} 09$, and $\mathrm{CP} 12$ specimens for each welding condition, where the main objective was to obtain the weld UTS and further compare with the base material mechanical properties. The samples were made according to ABNT NBR754927, and the tests were carried out on a SHIMADZU brand machine, with a maximum of $300 \mathrm{kN}$ capacity.

Vickers microhardness profile was measured in the CP07 specimen, which was taken from the best-welded joint (G4). The test parameters considered were: load 0.3 $\mathrm{Kg}$ and distance between indentations of $0.3 \mathrm{~mm}$. For the microstructural investigation, the sample was also prepared (sanding and polishing) and subsequently etched by Keller reagent $(1 \mathrm{ml}$ of hydrofluoric acid, $1.5 \mathrm{ml}$ of hydrochloric acid, $2.5 \mathrm{ml}$ of nitric acid and $95 \mathrm{ml}$ of distilled water).

Finally, samples from each condition were submitted to bending tests. Face bending was performed on $\mathrm{CP} 04$ and $\mathrm{CP} 10$, and root bending on $\mathrm{CP} 05$ and $\mathrm{CP} 11$ specimens. The purpose was to bend the samples up to $150^{\circ}$ without cracks or fractures.

\section{Results and Discussions}

\subsection{Top surface appearance}

Figure 4 shows the top surface appearance of the joints, where it was observed the flash formation as a function of welding conditions. Weld G3 showed a sharp flash in comparison to the previous joints obtained (G1 and G2).

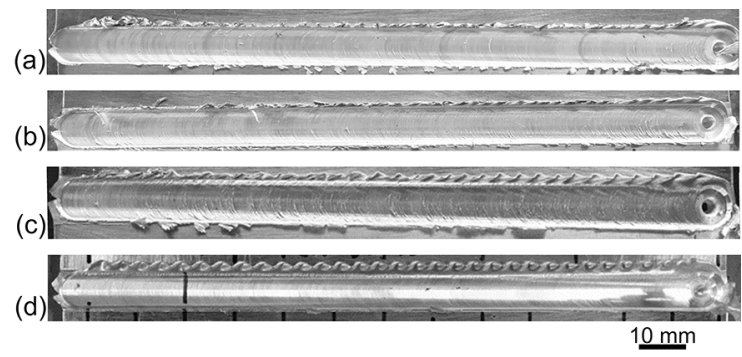

Figure 4. Top surface appearance of the welds: a) G1, b) G2, c) G3 and d) G4.

After this welding experiment (G3), it was verified that the probe crossed the welded plates, a fact that can explain the power oscillation and the flash occasioned. At last, the weld G4 presented the highest flash formed, however, in contrast to the other attempts, it has reached the best top surface finish, resulting in an almost polished shape in the final $80 \mathrm{~mm}$ of the weld length. It should also be mentioned that the non-monitoring of axial force may have influenced the flash formation since it becomes a parameter without control and can affect the weld production.

\subsection{Macrostructure}

In general, as shown in Figure 5, the weld macrostructures presented a good mixing within the stirred zone, and no voids or cracks were found in the samples located in the center of the welded length (a more stable region). However, even in visual assessments, some differences between the joints were noted.
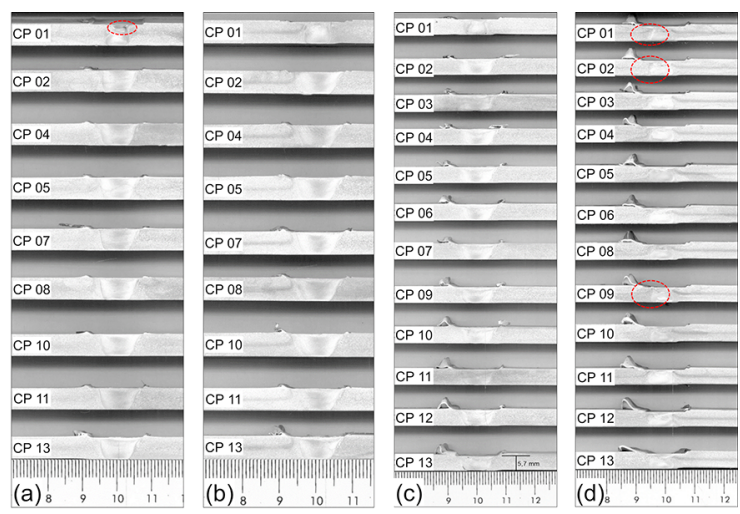

Figure 5. FSW macrostructures: (a) G1, (b) G2, (c) G3 and (d) G4.

Macrostructural analyzes of the weld G1 displayed an irregularity in the $\mathrm{CP} 01$, a fact that may have occurred due to cutting proximity of this sample to the dive site of the tool (Figure 4a). Regarding the weld G2 (Figure 4b), a slight improvement was obtained in a visual evaluation (compared to the weld G1). In weld G3, the presence of iron particles in CP13 (Figure 4c)) was observed, possibly due to the contact between the probe and the base material 
support. Finally, small voids formation was noted in some specimens of the weld G4 (Figure 4d). These defects may have occurred due to some inclusions or impurities in the joint ${ }^{27}$.

A study of the base material position effect on friction stir welds of dissimilar aluminum alloys showed that the material's mixing patterns in the joints might be different ${ }^{27}$ depending on the alloy location. Therefore, in the present work, which has considered the welding of similar aluminum alloys, when the lower strength alloy (AA5052-O) was located on the AS, and the alloy with higher mechanical properties on the RS (AA5083-O), the materials were better mixed. It can be further verified in Figure 5 by an improved average UTS (from the G3 to G4 experiment).

\subsection{Tensile testing}

Figure 6 illustrates the average UTS for all the welds. The weld G1 samples exhibited lower UTS than expected, and the rupture occurred in the weld region, which indicates unsuitable welding conditions. On the other hand, the weld G2 obtained higher average UTS in comparison to that of the weld $\mathrm{Gl}$, but the results remained unsatisfactory to the weld qualification. Therefore, the samples after tensile tests can be observed in Figure 7.

Changing the tool probe geometry promoted variations in tensile tests findings, and the weld G3 was able to withstand a mean UTS of $188.6 \mathrm{MPa}$. Therefore, the tool

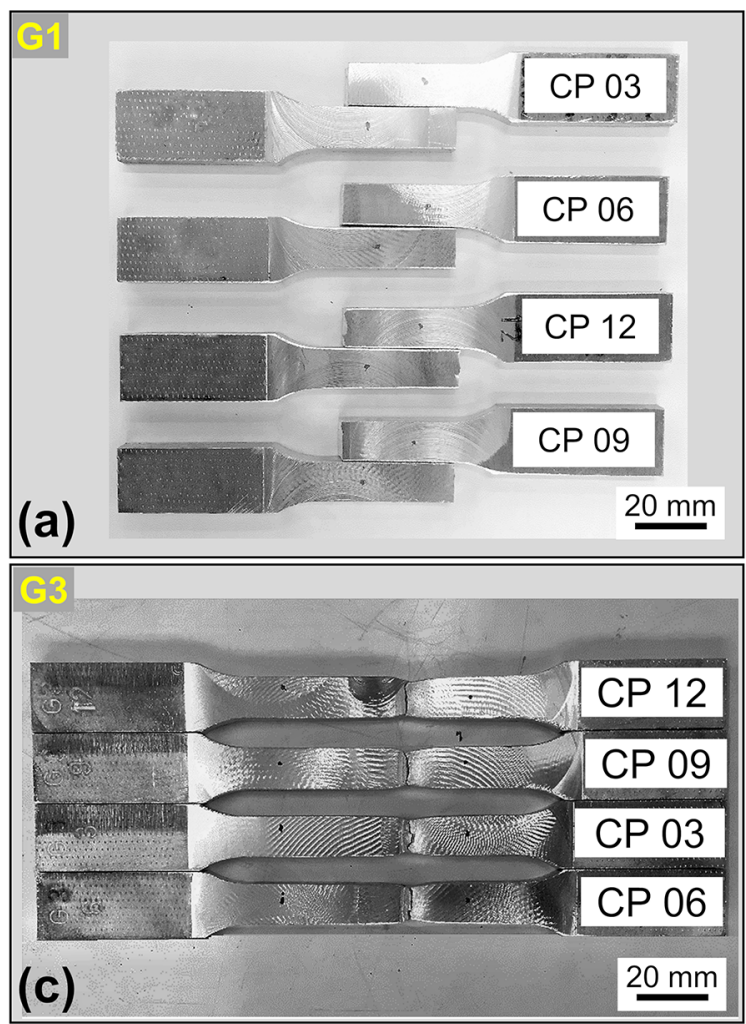

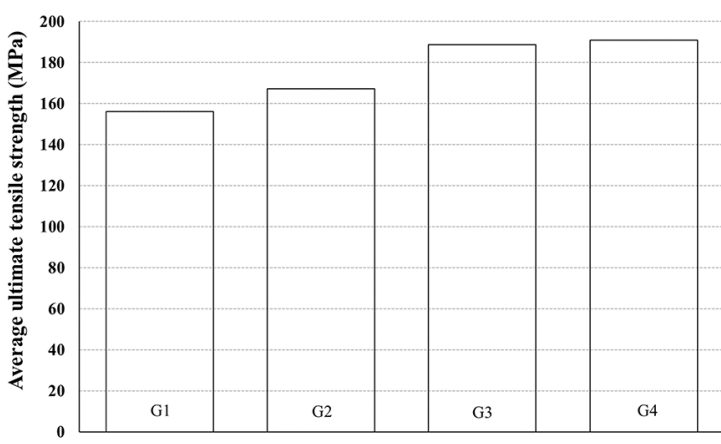

Figure 6. Average UTS according to FSW process conditions.

probe characteristics are fundamental for obtaining adequate joints. Also, all the specimens fractured in the AA5052-O alloy, outside of the stir zone. In weld G4 case, the average UTS was even higher, approximately of $191 \mathrm{MPa}$, and all the ruptures occurred on the opposite side, but likewise on the AA 5052-O alloy (due to the base material location inversion), facts that corroborate to the best weld quality. Moreover, as expected, the fractures were in the weak material ${ }^{28}$. Still, the average UTS reached by the welded joints G3 and G4 was above the minimum UTS of AA5052-O alloy (170 MPa- refer to Table 1). Finally, as can also be noted in Figure 7, the majority of these specimens (weld G3 and G4) broke at the base material and achieved the requirements as suggested in ${ }^{29}$.
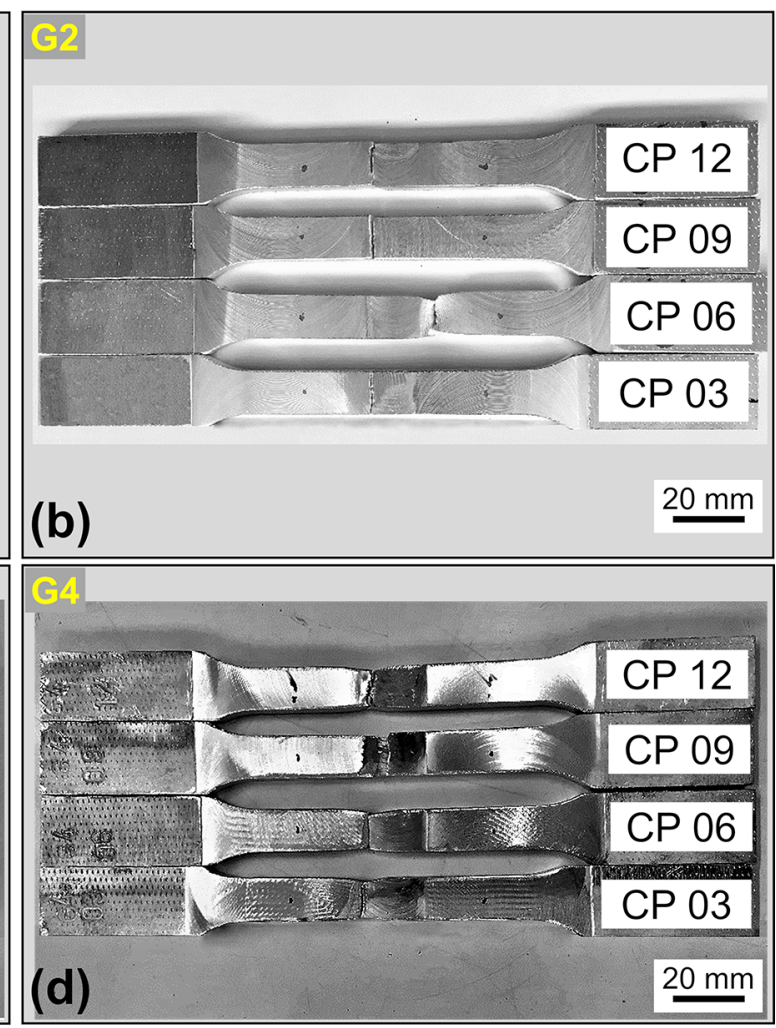

Figure 7. Samples after tensile testing: a) G1, (b) G2, (c) G3, and (d) G4. 


\subsection{Microhardness and microstructure}

Macrostructure and microhardness profile of the best joint (G4) are presented together, as can be noted in Figure $8 b)$. Regarding the base materials, distinct alloys were etched in a different manner, i.e., distinguishable colors, as can be observed in Figures 8b), c), and d). Non-uniform material flow can also be recognized near the top surface, which is probably related to the $\mathrm{CNC}$ machine limitations (tool tilt angle of $0^{\circ}$ ).
Furthermore, microstructural features of selected regions are displayed in Figures 8a), c), and d). In this sense, finer grains were verified in the stir zone (Figure 8a)). Therefore, the FSW application to similar aluminum alloys (AA5083-O and AA5052-O) was effective, promoting grain refinement, increased microhardness, and improved average UTS. Hence, the highest microhardness value ( 78 $\mathrm{Hv}$ ) was identified in the weld zone.

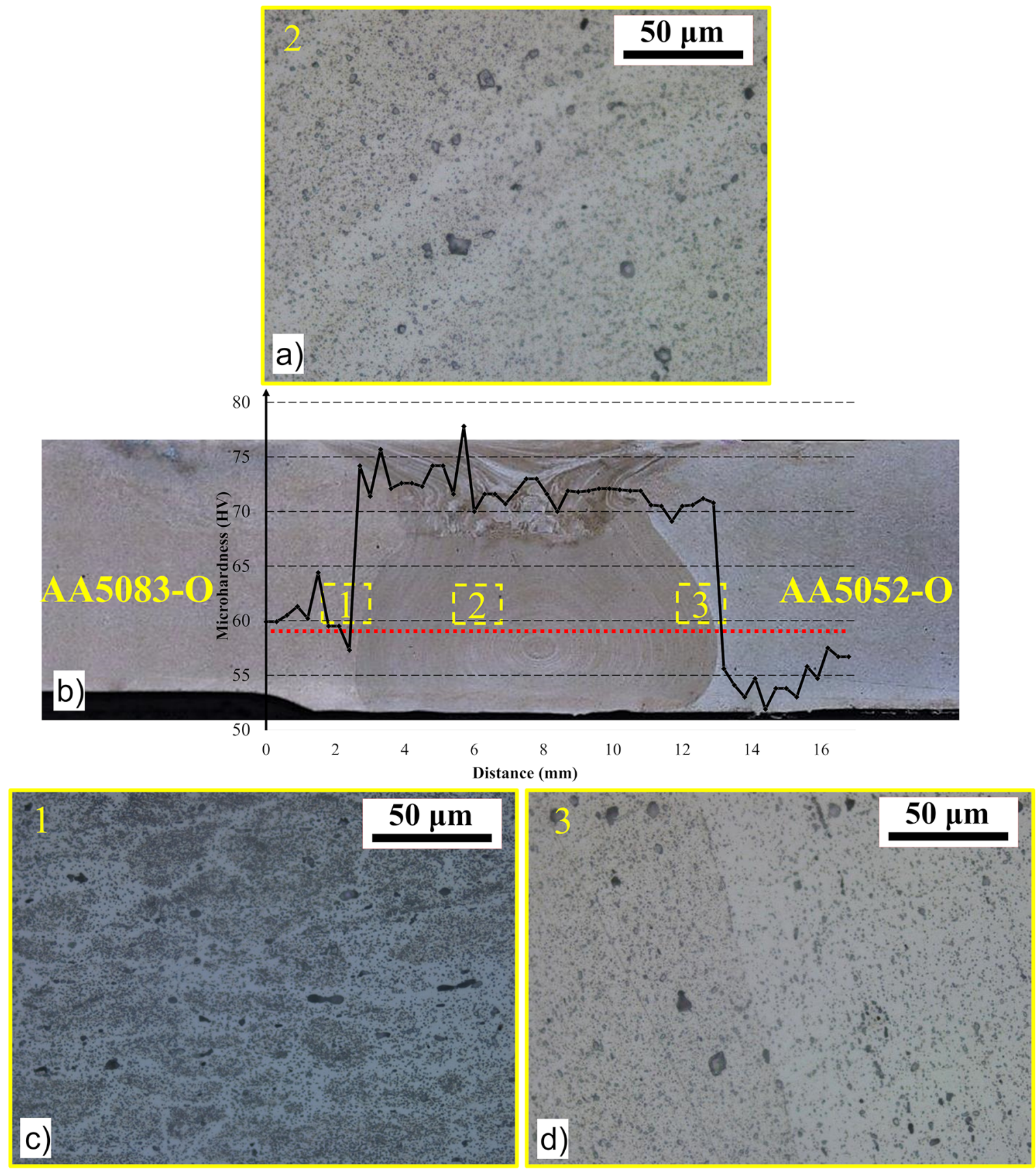

Figure 8. Weld G4: (a) stir zone, (b) macrostructure and microhardness - red line represents Vickers measurements, (c) AA5083-O interface, and (d) AA5052-O interface 


\subsection{Bending tests}

As can be seen in Figure 9, the G1 and G2 samples reached root bent angle of $150^{\circ}$, without any cracking. However, in face bending, the samples of these welding experiments broke at the beginning of the test. Further, an improvement in weld G2 was observed in relation to the weld G1, showing that the preliminary machining step is beneficial. In weld G3 and G4 specimens, a bent angle of around $150^{\circ}$ was reached, both face and root, indicating that the tool probe geometry is of great importance for achieving high-quality joints.

All the above results reported attempts to the qualification of friction stir welding to similar AA5083-O and AA5052-O aluminum alloys. There were important aspects toward the weld qualification and to achieve a satisfactory joint condition such as plate surface finish, tool probe geometry, and base material location (AS or RS). Furthermore, the weld processed in G4 experiment can be considered qualified and was chosen as the best joint, based on its suitable top surface quality, macrostructure, enhanced microhardness and UTS, and approval in bending tests.
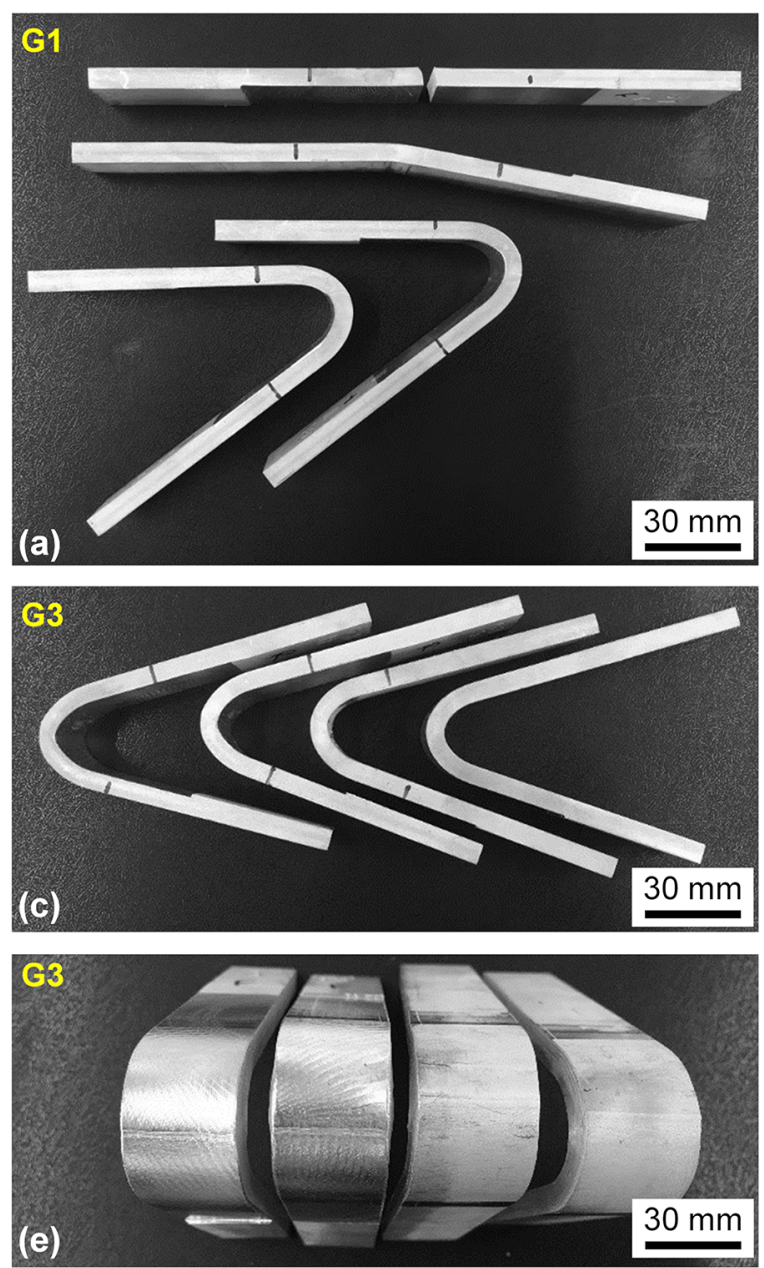

\section{Conclusions}

FSW was successfully applied to similar AA5083-O and AA5052-O aluminum alloys. The results of the present work can be understood as follows:

* Using surface machining practice on the plates, before welding, resulted in improvement in welds G1 and G2 results, due to the elimination of oxides and impurities in the aluminum surfaces and also to prior plates alignment.

* Tool probe geometry is essential for producing good weld quality;

* In initial welding experiments (G1 and G2), most of the specimens subjected to tensile testing broke at the weld centerline, with an average UTS of 156 and $167 \mathrm{MPa}$, respectively. Still, these welds were not approved in face bending tests, as they did not reach a bent angle of $150^{\circ}$;

* Welds G3 and G4 obtained similar results in tensile testing. As an average, the UTS of these experiments was para 188 and $190 \mathrm{MPa}$, respectively. Moreover, regarding bending tests, the joints G3 and G4 achieved satisfactory results, both face, and root bending. Finally, the joint G4 presented the highest average UTS, may be considered qualified and was selected as the best weld.
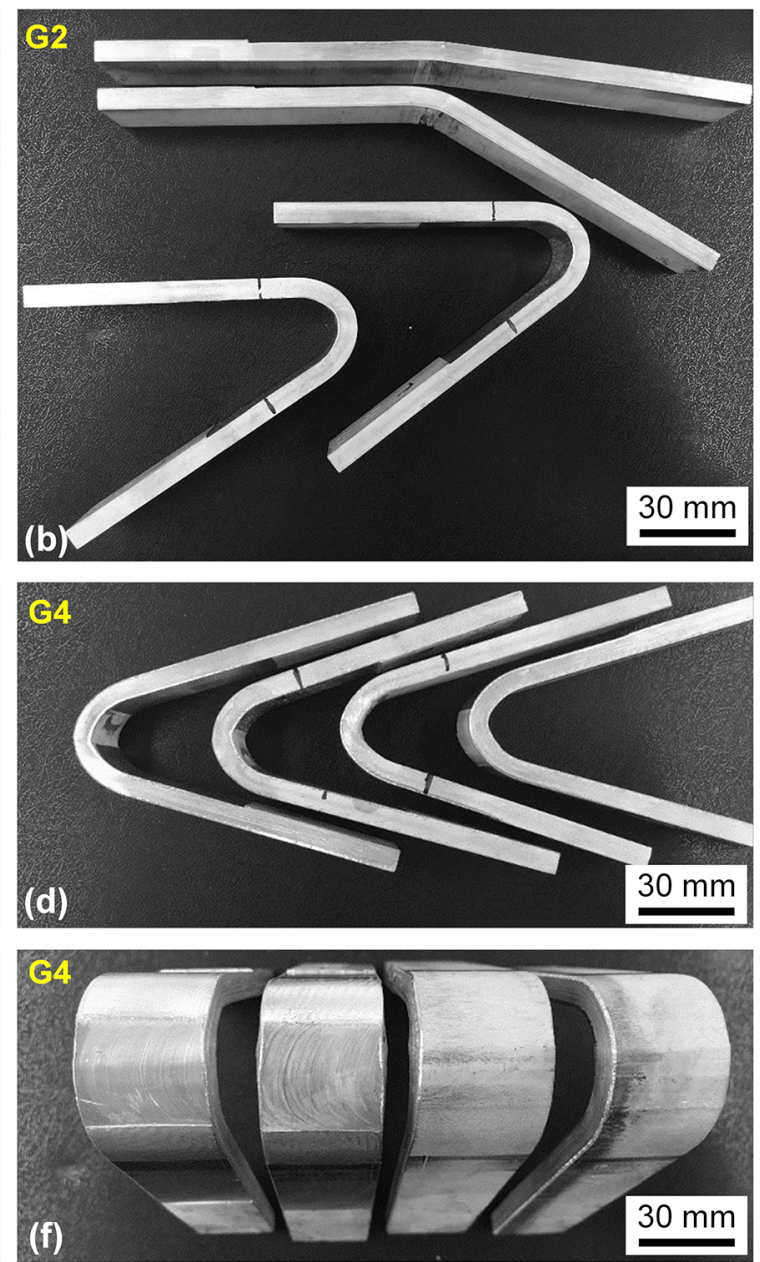

Figure 9. Welded samples after bending tests: (a) G1, (b) G2, (c) G3, and (d) G4. 


\section{Acknowledgements}

The authors would like to acknowledge the financial support of CAPES (National Council for Scientific and Technological Development - grant number 23038.000341/2019-71)

\section{References}

1. Associação Brasileira de Alumínio (ABAL). Anuário estatístico ABAL 2016. São Paulo: ABAL; 2017. Available from: <http:// abal.org.br/publicacao/anuario-estatistico-abal-2016>.

2. Khan NZ, Siddiquee AN, Khan ZA. Friction Stir Welding Dissimilar Aluminum Alloys. Boca Raton: CRC Press; 2017. DOI: https://doi.org/10.1201/9781315116815

3. Oliviecki NJ, Beskow AB. Análise dos parâmetros do processo de solda por fricção em uma liga de alumínio. Revista Perspectiva. 2013;37(138):15-29.

4. Thakur R, Bajwa PS. Friction stir welding of 5xxx series aluminium alloys. A literature survey. International Journal of Scientific Research in Science. 2016;2(2):1129-1131.

5. Valenciani VC. Ligações em estruturas de aço. [dissertation]. São Carlos: Faculdade de Engenharia de Estruturas, Escola de Engenharia de São Carlos, Universidade de São Paulo; 1997.301 f.

6. Lemos GVB, Hanke S, dos Santos JF, Bergmann L, Reguly A, Strohaecker TR. Progress in friction stir welding of Ni alloys. Science and Technology of Welding and Joining. 2017;22(8):643657. DOI: https://doi.org/10.1080/13621718.2017.1288953

7. National Aeronautics and Space Administration (NASA). Space Shuttle Technology Summary. Friction Stir Welding. Washington: NASA; 2001. http://www.nasa.gov/centers/ marshall/pdf/104835main_friction.pdf

8. Thomas WM, Kallee SW, Staines DG, Oakley PJ. Friction stir welding - process variants and developments in the automotive industry. In: 2006 SAE World Congress; 2006 Apr 3-6; Detroit, MI, USA. SAE Technical Paper 2006-01-0555. DOI: https:// doi.org/10.4271/2006-01-0555

9. Lohwasser D, Chen Z, eds. Friction stir welding from basics to applications. Oxford: Woodhead Publishing; 2010.

10. Pacchione M, Telgkamp J. Challenges of the Metallic Fuselage. In: $25^{\text {th }}$ Congress of International Council of the Aeronautical Sciences; 2006 Sep 3-8; Hamburg, Germany.

11. Dilger DE. Apple slims down iMac $40 \%$ with 'friction-stir welding' \& ditching the disc drive. Appleinsider; 2012. Available from: $\mathrm{http}$ //appleinsider.com/articles/12/10/24/apple-slims-downimac-40-with-friction-stir-welding-ditching-the-disc-drive

12. Cui L, Fujii H, Tsuji N, Nogi K. Friction stir welding of a high carbon steel. Scripta Materialia. 2007;56(7):637-640. DOI: https://doi.org/10.1016/j.scriptamat.2006.12.004

13. Lee WB, Yeon YM, Jung SB. The joint properties of dissimilar formed $\mathrm{Al}$ alloys by friction stir welding according to the fixed location of materials. Scripta Materialia. 2003;49(5):423-428. DOI: https://doi.org/10.1016/S1359-6462(03)00301-4
14. Çevik B, Özçatalbaş Y, Gülenç B. Friction Stir Welding of 7075-T651 Aluminium Alloy. Practical Metallography. 2016;53(1):6-23. DOI: https://doi.org/10.3139/147.110363

15. Çevik B, Özçatalbaş Y, Gülenç B. Effect of tool material on microstructure and mechanical properties in friction stir welding. Materials Testing. 2016;58(1):36-42. DOI: https:// doi.org/10.3139/120.110816

16. Çevik B, Ozcatalbas Y, Gülenç B. Effect of welding speed on the mechanical properties and weld defects of $7075 \mathrm{Al}$ alloy joined by FSW. Kovove Materialy. 2016;54(4):241-247. DOI: https://doi.org/10.4149/km_2016_4_241

17. Azimzadegan T, Serajzadeh S. An Investigation into Microstructures and Mechanical Properties of AA7075-T6 during Friction Stir Welding at Relatively High Rotational Speeds. Journal of Materials Engineering and Performance. 2010;19(9):1256-1263. DOI: https://doi.org/10.1007/ s11665-010-9625-1

18. Lee WB, Lee CY, Chang WS, Yeon YM, Jung SB. Microstructural investigation of friction stir welded pure titanium. Materials Letters. 2005;59(26):3315-3318. DOI: https://doi.org/10.1016/j. matlet.2005.05.064

19. Hanke S, Lemos GVB, Bergmann L, Martinazzi D, dos Santos JF, Strohaecker TR. Degradation mechanisms of pcBN tool material during Friction Stir Welding of Ni-base alloy 625. Wear. 2017;376-377(Pt A):366-371. DOI: https://doi. org/10.1016/j.wear.2017.01.070

20. Lemos GVB, Farina AB, Nunes RM, da Cunha PHCP, Bergmann $\mathrm{L}$, dos Santos JF, et al. Residual stress characterization in friction stir welds of alloy 625. Journal of Materials Research and Technology. 2019;8(3):2528-2537. DOI: https://doi. org/10.1016/j.jmrt.2019.02.011

21. Aonuma M, Nakata K. Dissimilar Metal Joining of 2024 and 7075 Aluminium Alloys to Titanium Alloys by Friction Stir Welding. Materials Transactions. 2011;52(5):948-952. DOI: https://doi.org/10.2320/matertrans.L-MZ201102

22. Sato YS, Park SHC, Michiuchi M, Kokawa H. Constitutional liquation during dissimilar friction stir welding of $\mathrm{Al}$ and Mg alloys. Scripta Materialia. 2004;50(9):1233-1236. DOI: https://doi.org/10.1016/j.scriptamat.2004.02.002

23. Li XW, Zhang DT, Qiu C, Zhang W. Microstructure and mechanical properties of dissimilar pure copper/1350 aluminum alloy butt joints by friction stir welding. Transactions of Nonferrous Metals Society of China. 2012;22(6):1298-1306. DOI: https:// doi.org/10.1016/S1003-6326(11)61318-6

24. METALTHAGA. Composição química das ligas de alumínio. Novo Hamburgo: METALTHAGA; 2015. Available from: $<$ http://metalthaga.com.br/wp-content/uploads/2015/11/1Composicao-Quimica-das-Ligas-de-Aluminio.pdf $>$.

25. METALTHAGA. Propriedades mecânicas das ligas de alumínio laminadas. Novo Hamburgo: METALTHAGA; 2017. Available from: $<$ http://metalthaga.com.br/wp-content/uploads/2017/12/5Propriedades-Mecanicas-Ligas-de-Aluminio-Laminadas.pdf>.

26. International Organization for Standardization (ISO). ISO 25239-4 - Friction stir welding - Aluminium - Part 4: Specification and qualification of welding procedures. Geneva: ISO; 2011. 
27. Park SK, Hong ST, Park JH, Park KY, Kwon YJ, Son HJ. The effect of material locations on properties of friction stir welding joints of dissimilar aluminium alloys. Science and Technology of Welding and Joining. 2010;15(4):331-336. DOI: https://doi.org/10.1179/136217110X12714217309696

28. Zhao Z, Liang H, Zhao Y, Yan K. Effect of Exchanging Advancing and Retreating Side Materials on Mechanical Properties and
Electrochemical Corrosion Resistance of Dissimilar 6013-T4 and 7003 Aluminum Alloys FSW Joints. Journal of Materials Engineering and Performance. 2018;27(4):1777-1783. DOI: https://doi.org/10.1007/s11665-018-3253-6

29. American Bureau of Shipping (ABS). Guide for the Approval of Friction Stir Welding in Aluminum. Houston: ABS; 2011. 